\title{
BEYOND GAMIFICATION: CLASSCRAFT AS AN ENGAGEMENT TOOL IN THE TEACHING OF ENGLISH AS A SECOND LANGUAGE
}

\author{
Verónica Membrive, \& Madalina Armie \\ Department of English Studies, University of Almeria (Spain)
}

\begin{abstract}
The educational use of gamification in class has been widely explored by research. Deterding (2012), Cronk (2012), or Stott and Neustaedter (2013), are only some of the experts on the field that have established in their theorizations a direct relationship between gamification and higher levels of motivation and engagement of students regardless their educational levels. When teaching English as a second language, gamification becomes a key factor to provide dynamism to lessons and to foster the consolidation of the contents taught in class. Moreover, gamification not only promotes the assimilation of vocabulary and grammar (Abrams \& Walsh, 2014), but also the improvement of oral and written comprehension and production (Mazur, Rzepka \& Araki, 2011; Grouling, Hedge \& Schweigert, 2014). The extensive use of new technologies in class nowadays has proved to be very useful for the implementation of the methodology on gamification. One of the tools that have got the attention of educators in recent years is Classcraft, an online virtual game based on digital storytelling in which students and educators can interact with a two-fold purpose: to promote participation in class, and to propose activities for the learning and consolidation of contents. This paper aims at explaining and assessing the use of Classcraft as a successful technology-based collaborative learning tool in a course on English as a Second Language at university level. The following pages are to provide an explanation for the design and implementation of Classcraft in a group of 35 students with a B2 level according to the CEFRL, for a course on English for Specific Purposes (Academic English) at a Spanish University for one semester. Classcraft has been used here to increase motivation and attention in the classroom, to promote students' participation as well as their ability to work in groups, solve challenges, while encouraging the development of students' personal qualities such as persistence, creativity and resilience through extended play.
\end{abstract}

Keywords: Gamification, classcraft, motivation, ESL, methodology.

\section{Introduction}

Teaching a second language nowadays requires creativity, a great amount of attractive resources, and distinctive approaches that attempt to intermingle old methodologies and new techniques. This created situation in which teaching finds itself under continuous pressure and necessity for innovation is much marked and propelled by the vertiginous technology transformation affecting classrooms everywhere around the world.

As an attempt to solve existent problems of the schooling system, theorisations on the learner and motivation in the classroom attempt to go beyond the traditional classifications of the latter in intrinsic and extrinsic, and its valuation in terms of social and emotional conditionings. By investigating students' engagement in classroom, and by highlighting the obsolescence and ineffectiveness of traditional schooling approaches (Lee \& Hammer, 2011), a connection can be observed between the latter mentioned elements and problems of levels cheating, disengagement from school, and with this, higher attrition rates.

The implementation of games and gamification in the educational institutions might offer an answer for the solving of some of these quandaries regarding class planification, management, teaching and learning, considering that games are desirable experiences that set into motion motivational mechanisms which engage learners of English as a second language since they provide dynamism to the lessons and foster through play the consolidation of contents. This formerly alluded widespread use of new technologies has proved to be strongly useful for the implementation and diversification of the methodology of gamification in the classroom. 
One of the tools that follow these principles of motivation and engagement in the classroom that has got the attention of educators lately is Classcraft, an online virtual game based on digital storytelling where both, learner and educator can interact.

The following pages aim at explaining and assessing the use of Classcraft as a successful technology-based collaborative learning tool in a course of English as a Second Language at university level. The first step of this study would be to review literature related to the use of gamification in general, and later in education and ESL teaching. Further sections of this paper are to explain the design and implementation of Classcraft in a group of 35 students, taking a course on English for Specific Purposes (promoting the acquisition of Academic English) at a Spanish University for one semester. Considering the framework of six-point scale or levels of proficiency of the Council of Europe, the students of the case study must attain a B2 level.

Subsequently, are to be explored several questions regarding the designing and the distribution of tasks in order to work on the four language skills to acquire the level required to pass the course successfully, but also a concluding analysis on the students' impressions on ESL teaching previously to the implementation of the game and after the process in order to assesses Classcraft's usefulness and its degree of success as a methodology for the teaching of a second language.

\section{Beyond definitions. Uses and applications of gamification in education}

According to (Deterding, Dixon, Khaled \& Nacke 2011:1) the term gamification was used for the first time in 2008, although it was popularised only in the second part of the year 2010 due to games' booming expansion in the world of digital media and industry. Their success and merging with real life from that moment was such, that Jesse Schell, a game designer, professor and visionary spoke in 2010 in an interview to CNN about an imminent "gameapocalypse [,] where every second of your life you're playing a game in some way (Sutter and Schell 2010).

This affirmation is definitely not hyperbolic if considering that nowadays gamification is part of the contemporary lifestyle and a rapidly growing dimension of daily reality with applications working in diverse fields such as "business, marketing, corporate management, and wellness and ecology initiatives [...as an attempt to] shape user's behaviour in a desirable direction" (Dicheva, Dichev, Agre and Angelova 2015:2) by praising players with badges, discounts and other rewards for visiting real world shops and "checking-in" to the mobile application" (Lee and Hammer 2011:1). Considering this mechanism therefore, gamification proposes the experimentation with rules, emotions and roles within an ambit characterised by "the use of game design elements in non-game contexts" (Deterding et al., 2011).

Despite its success in other spheres like those previously mentioned, there has been hardly any academic attempt to provide an immediate definition of gamification or an assessment of its possible applications and roles within the schooling system until relatively very recently. The educational use of gamification in class has been explored by scholars of the field such as Deterding (2012), Cronk (2012) or Stott and Neustaedter (2013) among others. Their studies have contributed to construction on the theorisation of a relationship between gamification and a higher level of motivation and engagement of students from different educational levels since it has been demonstrated that "video games and virtual worlds excel at engagement (McGonigal 2011). Furthermore, it has been illustrated how gamification promotes the assimilation of vocabulary and grammar (Abrams \& Walsh, 2014), and improves oral and written comprehension and production (Mazur, Rzepka \& Araki, 2011; Grouling, Hedge \& Schweigert, 2014). Also, it will be interesting to mention that bibliography on the subject affirms that positive side effects of this transmission and learning of contents through playing are numerous. Frequently, games work at different levels since they combine mental and physical exercises, provide immediate feedback, they offer the chance to satisfy curiosity by reasoning and solving problems, and offer a sense of progress and satisfaction associated with the possibility of success when these challenges are overcome. Moreover, games incite to collaboration and communication, while promoting the development of personal qualities such as persistence, creativity and resilience through extended play (McGonigal 2011).

As regarding the disadvantages of this innovative methodology or the pitfalls of gamification, it is worth mentioning not only the adaption of the game itself to the class's necessities, objectives and contents is tedious, but also its implementation during the different sessions which is time consuming for the teacher. Moreover, to these aspects must be added the fact that using games as resources for teaching might be expensive (Kapp, 2012).

The role of gamification within the educational system and also its success comes from the understanding of the role of game elements designed in relation to the learning behavior of students, the contents and objectives of the subject being taught and class dynamics. In order to explain the theoretical rationale behind gamification when referring to education, "badges" must be perceived as being grades regularised by a system of rewards for desired behaviours, and by the contrary as punishments for 
undesirable ones. Just in the same way as games, educational systems use grading systems conditioned by specific criteria that value the achievement of the objectives of the curriculum by accumulating points that result into a final mark. These elements of grading and accumulation of marks can be transformed in formal education into a gamified experience where students might feel motivated while enjoying the learning process. Under this refocus "levelling up" in the game would be the equivalent of passing the subject at the end of every academic year. Starting therefore from the premise that "within the context of games, players voluntarily invest countless hours in developing their problem-solving skills for levelling up and reaching their final goals" (Gee 2008), games can be transformed into valuable learning tools with other multiple and positive side effects as the following pages are going to reveal.

\section{Classcraft as educational tool}

Classcraft is an educational online tool available to educators to use in the classroom. It is designed to act as a complement to regular lessons and its main purpose is to foster active participation, teamwork and engagement. Besides, Classcraft allows educators to gamify a complete course, add only specific gamified activities or entire teaching modules; thus, it was chosen because of its adaptability to educators' teaching needs and its usefulness to explore the effectiveness of the combination of gamification and video games in an ESL context.

This study pretends to analyse, qualitatively and quantitatively, the degree of motivation before and after the implementation of the game when compared to traditional teaching practices. The sample group for this intervention was composed of 35 undergraduate students (18 to 26 years old) who took a course on Academic English as part of their regular academic load in a Spanish university. This group was chosen because of its accessibility for the researchers and because of a considerable number of its newly arrived students who were not motivated. The intervention took place once a week (60 minutes) for a period of 15 weeks. Spoken and written production and comprehension were part of the daily schedule and proposed activities. The first session was devoted to eliciting Classcraft's regulations and functionality.

Prior to the experiment, students filled out a survey composed by eleven close-ended questions where were studied student's general conceptualisation and enthusiasm towards English lessons and different traditional and current teaching methodologies. Besides, they were also asked to pinpoint their observations regarding cooperation and competition in learning, teamwork and working on online assignments. Finally, students had to expose their degree of interest in games and rewards, and videogames as tools to learn English. Similarly, a post-intervention survey composed by thirteen close-ended questions was designed to value the impact of the tool on the students' acquisition and learning process, insisting upon the degree of stimulation and significance of the content of the activities, the usability of the tool after the experiment and whether or not students would recommend the use of this tool in other English courses.

Results from the survey before the intervention reveal that all students $(34,7 \%$ strongly agreed and $65,3 \%$ agreed) like taking English courses at a university level. A $23 \%$ of the students marked that the learning process was better with the use coursebooks and worksheets, while there was a majority of $55 \%$ who disagreed. In relation to activities implemented in class, $100 \%$ of students strongly agreed on the fact that these should be appealing and motivating for students. Post-intervention results show that almost all students enjoyed the use of Classcraft in class ( $92 \%$ strongly agreed and $8 \%$ agreed), and that they liked the creation of the story that guided them towards the final reward. The design and content of activities was significant and stimulating for $78 \%$ of students, and most of them would like to implement Classcraft as part of their regular English lessons (88\%). Regarding students' motivation, an $86 \%$ of the respondents claimed to be highly interested in learning English through the use of this tool, and a 14\% expressed an average enthusiasm when asked.

This tool has proven to be a very useful and motivating resource to teach English as a second language, however, Classcraft might not be very interactive for students since characters remain static as they go through each quest. Besides, reward mechanics is only useful for instant feedback in class, and it can become very complex for students at the beginning. Even if students are able to design and customize their own character, available options are limited and some powers cannot be customized. 


\section{Conclusion}

This paper presents a case study which attempts to discuss gamification in the English class as a strategy to foster motivation among students. In particular, the educational videogame Classcraft has been selected to encourage students to be active participants and work in teams. The competitive environment of the class has also been useful to improve students' behavior in class. Regarding its usability to teach English, the videogame has been used to work on both written and oral production and comprehension.

Data analysis before and after the intervention shed light on very remarkable effects of the tool in class. It could be claimed that as the literature review points out, gamification has the prospective to intensify students' second language acquisition and to improve their abilities. Besides, as Buckley and Doyle (2014) assert, virtual games influence positively students' outcomes. The paramount benefit of applying gamification in class relies on its capability of improving students' enthusiasm, teamwork, and language acquisition and, as Kapp (2012) rewards and competition also have important effects on students' engagement with classroom resources. All these mentioned aspects could be observed in the conducted surveys.

\section{References}

Abrams, Sandra Schamroth, \& Walsh, Sara. (2014). Gamified Vocabulary. Journal of Adolescent \& Adult Literacy $581,49-58$.

Buckley, P., \& Doyle, E. (2014). Gamification and Student Motivation. Interactive Learning Environments 3, 1-14.

Cronk, Marguerite. (2012). Using Gamification to Increase Student Engagement and Participation in Class Discussion. EdMedia+: Innovate Learning Association for the Advancement of Computing in Education (AACE), 311-315.

Deterding, S. (2012). Gamification: Designing for Motivation. Interactions, 19 4, 14-17.

Deterding, Sebastian, et al. (2011). From Game Design Elements to Gamefulness: Defining Gamification. Proceedings of the 15th International Academic MindTrek Conference: Envisioning Future Media Environments, 9-15.

Dicheva, D., Dichev C., Agre G., \& Angelova G. (2015). Gamification in Education: A Systematic Mapping Study. Educational Technology \& Society, 18 3, 75-88.

Gee, J. P. (2008). Learning and games. In Katie Salen (Ed.), The Ecology of Games: Connecting Youth, Games, and Learning (John D. and Catherine T. MacArthur Foundation Series on Digital Media and Learning). Cambridge, MA: The MIT Press.

Grouling, J., Hedge, S., Schweigert, A., \& Snider, E. G. (2014). Questing through Class: Gamification in the Professional Writing Classroom. Computer Games and Technical Communication: Critical Methods and Applications at the Intersection, 265-82.

Kapp, K. M. (2012). The Gamification of Learning and Instruction: Game-based Methods and Strategies for Training and Education. San Francisco: Pfeiffer.

Lee, J. J., \& Hammer, J. (2011). Gamification in education: What, How, Why Bother? Definitions and Uses. Exchange Organizational Behavior Teaching Journal, 15 2, 1-5.

Mazur, Michal; Rzepka, Rafal; Araki, Kenji. (2011). Proposal for a Conversational English Tutoring System that Encourages User Engagement. Proceedings of the 19th International Conference on Computers in Education, 10-12.

McGonigal, J. (2011). Reality is Broken: Why Games Make us Better and How They Can Change the World. London: Penguin.

Stott, Andrew, and Carman Neustaedter. (2013). Analysis of Gamification in Education. Canada 8, 1-8.

Sutter, John D., and Jesse Schell. "Why Games Will Take over Our Lives." CNN, Cable News Network, 5 Apr. 2010, edition.cnn.com/2010/TECH/04/05/games.schell/index.html. 